\title{
Introduction to the Special Issue Spotlighting Papers from the AERA Special Interest Group on Online Teaching and Learning
}

\author{
Karen Swan \\ University of Illinois Springfield \\ Jennifer Richardson \\ Purdue University
}

The American Educational Research Association (AERA) is the premier association of educational research professionals. Founded in 1916, AERA has more than 25,000 members and is international in scope, with members representing over 85 countries world-wide. It is concerned with improving the educational process by encouraging scholarly inquiry related to education and evaluation, and by promoting the dissemination and practical application of research results. AERA's 2017 annual meeting, held in San Antonio, TX, included thousands of research presentations across a range of disciplines.

AERA supports 12 divisions and 150 Special Interest Groups (SIGs). One of the latter is the Special Interest Group on Online Teaching and Learning (SIG-OTL). SIG-OTL is a multidisciplinary community of scholars focused on the creation, use, and evaluation of online learning environments. (For more information on AERA and SIG-OTL, visit the SIG-OTL website at: http://www.aera.net/SIG035/Online-Teaching-and-Learning-SIG-35 or the SIG-OTL Facebook page at https://www.facebook.com/AERAOTL/). In 2017, SIG-OTL accepted 65 papers from 101 submissions and sponsored 15 sessions in which researchers presented their findings on a variety of topics related to online learning.

For the past two years Online Learning (OLJ) has published a selection of high quality papers presented at AERA through a cooperative arrangement between the Online Learning Consortium and SIG-OTL. Special thanks to the SIG Chair, Steven Terrell, of Nova Southeastern University for his assistance. The eleven papers in this special issue were selected from accepted papers. They include research on online collaboration from the perspectives of minority students and instructors, on how perceptions of communities are influenced by course length and discussion facilitation, and on the relationship between self-reflection and achievement in online K-12 math courses. There are two papers on online teachers' professional development - one exploring best practices and the other opportunities for learning how to support students with disabilities online - and three interesting studies that explore fascinatingly different versions of "hybrid" learning ranging from the accommodation of students who became distant, the use of "robot-mediated communication," and virtual office hours. Finally, there are two papers on MOOCs, one offering a typology for categorizing MOOCs and the other exploring the relationship between student engagement and achievement in MOOCs. These are described below.

The first paper in this collection, "Online Collaborative Learning Activities: The Perspectives of Minority Graduate Students," reports on a qualitative study focusing on the 
perceptions of minority graduate students toward online collaborative activities. Authors Alex Kumi-Yeboah, James Dogbey, and Guangji Yuan found that the 20 African American, Hispanic and international students from Africa they studied felt collaborative activities helped meet their learning and communications style. The students also stated their preference for small group over whole group activities, their appreciation of opportunities to share and lead discussions, and their belief that collaborative activities support knowledge-building and construction. On the other hand, the students noted the challenges of dealing with cultural differences and reported a lack of cultural diversity and inclusion in the course materials and content. Read the article to find out about recommendations that instructors can use in their own courses.

The four instructors interviewed in Heather Robinson, Whitney Kilgore, and Scott Warren's study also provided perspectives on collaborative learning. In "Care, Communication, Support: Core for Designing Meaningful Online Collaborative Learning," the second paper in this section, the authors report that these instructors focused more than one might expect on technology issues in two of the three main themes that emerged from the study -- online communication approaches matter, challenges and supports for online collaborative learning, and care is at the core of online learner support. In this last category, all four discussed the importance of developing relationships with their students but also of providing scaffolding for collaboration.

The third paper in this collection is titled "Student Actions and Community in Online Courses: The Roles Played by Course Length and Facilitation Method." Its authors, Carrie Demmans Epp, Krystle Phirangee, and Jim Hewit take a primarily quantitative approach to studying the development of community in online discussion. Using a two (facilitation approach) by two (course length) design, they found that instructor-led (as opposed to student-led) facilitation and longer course lengths were associated with stronger student perceptions of community, but that facilitation approach had a stronger effect than course length. No interactions between main effects were found, but the authors noted that students' postings differed between groups.

The next paper in this collection deals with online learning in the K-12 arena. In "SelfReflection and Math Performance in an Online Learning Environment," Jinnie Choi, Alyssa Walters, and Pat Hoge report on a series of retrospective studies of full time virtual students enrolled in elementary, middle and high school mathematics classes in eight online schools in the United states. In particular, the authors were interested in whether or not participation in selfreflection activities embedded in these courses improved student performance. They found that participation in self-reflection varied by grade, unit test performance level, and course/topic difficulty; that more frequent participation in self-reflection and higher self-confidence levels were associated with higher final course performance; and that self-reflection showed limited impact for more difficult topics, higher grade levels, and higher performing students.

In "Describing K-12 Online Teachers' Online Professional Development Opportunities for Students with Disabilities," Mary Rice reports on a phenomenological study that explored professional development focused on teaching students with disabilities online. Based on several semi-structured interviews with 18 administrators and 14 teachers involved in K-12 online education, results revealed that most professional development in this arena was on an as needed basis and professional development concerned with disabilities mostly centered on legal responsibilities, and that participating teachers and administrators had little opportunity to improve their accommodation and instructional knowledge and skills. 
Turning to professional development in higher education, Sandra Mohr and Kaye Shelton recruited fifty-seven experts with at least five years' experience supporting online faculty for a four round Delphi study. In "Best Practices Framework for Online Faculty Professional Development: A Delphi Study," the outcome was the identification of four categories of professional development topics - faculty roles, classroom design, learning processes, and legal issues - and three categories of institutional strategies - campus climate, expectations for online learning, and staffing support.

Moving to hybrid environments we begin with a case study by Enilda Romero-Hall and Rocha Vicentini, "Examining Distance Learners in a Hybrid Synchronous Course: Successes and Challenges." The hybrid course studied was a tradition face-to-face course reconfigured using synchronous video and an LMS to accommodate three learners who due to various circumstances needed to complete their masters program as distance students. The study found that hybrid synchronous instruction improved the study habits of the distance learners. On the other hand, to succeed, the distance learners had to overcome pedagogical challenges involving the interactions, relationships, and communication exchanges between distance learners, their face-to-face counterparts, and the instructor.

In "Hybrid Education: The Potential of Teaching and Learning with Robot-Mediated Communication," Benjamin Gleason and Christine Greenhow explore hybrid learning in which 12 online and one campus-based doctoral students communicated using robots who occupied a physical space. Results from this fascinating study suggest that robot-mediated communication offers advantages over traditionally used video- conferencing, including affordances for fostering students' embodiment in the classroom, their feelings of belonging and trust, and their ability to contribute ideas in authentic ways.

Patrick Lowenthal, Joanna Dunlap, and Chareen Snelson also examined a hybrid environment, which integrated live synchronous web meetings into asynchronous online courses, collected student feedback, and made iterative changes over time based on that feedback. Their paper, "Live Synchronous Web Meetings in Asynchronous Online Courses: Reconceptualizing Virtual Office Hours," documents three successive redesigns of optional virtual office hours to increase student attendance. The authors conclude the paper with implications for practice, including providing orientation to live sessions from the beginning of the course, scheduling for a range of times, making the sessions relevant to students' learning needs, adding incentives (such as extra credit points), and making sure the sessions are highly interactive.

In the final shift of our special issue we look to MOOCs, beginning with Stephanie Blackmon and Claire Major's "Wherefore Art Thou MOOC: Defining Massive Open Online Courses. This study used a typology they developed to examine the public information about 30 MOOCs." The typology classifies MOOCs along ten dimensions - affiliation, size, accessibility, duration, timing, relation to knowledge, content, structure, authority and control, and pedagogy. The authors report that the typology was useful in general but that some categories such as affiliation, duration, and size needed revision. Some patterns that emerged were that MOOCs from particular providers generally shared pedagogical approaches, and that the size of MOOCs is related to who enrolls and is therefore independent of the other categories. The authors also found that the distinctions between cMOOCs and XMOOCs seem to be blurring.

Finally, Fernanda Cesar Bonafini, Chungil Chae, Eunsung Park, and Kathryn Weed Jablokow ask "How Much Does Student Engagement with Videos and Forums in a MOOC Affect 
Their Achievement?" Their answer is that both engagement with videos and participation in discussion forums are positively associated with achievement in MOOCs but both of these both of these behaviors are strongly influenced by students' intention to get MOOC certificates. The paper also reports on an interesting qualitative analysis of discussion posts, which reveals that most students' posts display more information acquisition than critical thinking. The authors suggest that MOOC instructors foster engagement in forums by implementing discussion prompts that foster interactions about the deep meaning of concepts or application of concepts covered.

The editors of this special issue hope our readers enjoy the articles selected and welcome any comments

- Karen Swan, Stukel Professor of Educational Leadership, University of Illinois Springfield; kswan4@uis.edu

- Jennifer C. Richardson, Professor, Learning Design and Technology program, Curriculum and Instruction Department, Purdue University; jennrich@purdue.edu

In closing, we would like to acknowledge the efforts of a number of individuals who made critical contributions to this special issue, particularly Sturdy Knight, Marquetta Straight, Shelley Rafferty Withers, and the staff of Online Learning. 